\title{
Cerebellar ataxia, Cayman type
}

INSERM

\section{Source}

INSERM. (1999). Orphanet: an online rare disease and orphan drug data base. Cerebellar ataxia, Cayman type. ORPHA:94122

Cerebellar ataxia, Cayman type is characterised by psychomotor retardation, hypotonia and cerebellar dysfunction (nystagmus, ataxic gait, truncal ataxia, dysarthric speech and intention tremor), associated with cerebellar hypoplasia. 